\title{
DO FIRM VARY THE FREQUENCY OF ADVERTISING IN AN OFFLINE AND ONLINE ENVIRONMENT? AN ANALYTICAL APPROACH
}

\author{
Sunday C. Eze and Angela Oduro-Gyamfi
}

Department of Business Systems, University of Bedfordshire, UK

\begin{abstract}
There have been countless developments in the field of communication and information. Marketers have been quick to capitalise on these advancements. In this regard, the interactive advertising has slowly been gaining prominence globally, and many companies now have online presence enabling them to gain recognition not only locally but also globally. This study has been an attempt at analysing the variations in the frequency of both the online and the offline medium of advertising, through the analysis of the companies' reports of two brands-Camden food co and The Pasty Shop. It was discovered that the common perception that exists is that online web-sites are expensive to maintain after initial implementation. The method of advertising is chiefly dependent on the marketing policy of a firm, which is actually a product of the nature of the firm itself. Hence, since both Camden Food Co and The Pasty Shop cater to people who are commuting and have a bite on the go, the key advertising strategy has been to invest in and maintain offline advertising.
\end{abstract}

KEYWORDS: firms, online, offline, advertising, Camden Food, Pasty Shop

\section{INTRODUCTION}

For some time now, the internet is playing an instrumental role in the sphere of business and marketing, particularly advertising. The traditional (offline) media (such as the print media as well as audio/visual) are now being challenged as never before due to the advent and widespread use of the Internet, often having critical consequences on the marketing strategy of a business. In the context of this study, the traditional media shall be taken in the realm of offline media while the Internet shall be considered as online media. The offline media that currently appears to be the most vulnerable is the newspaper industry, as shown by official statistics (Bergemann \& Bonatti, 2011). Many retailers have online stores as well, and the income from these online stores is also significant. For instance, Macy's annual growth rate in 2011 from physical outlets was reported at $6.7 \%$ while the online stores indicated an annual growth rate of almost 45\% (Macy's Press Release, 2011). Online sales growth is challenged only by the spending on online advertising. Financial reports give evidence to the fact that while many firms have been forced to decrease their marketing budgets due to the global financial crisis, spending on online advertising has conversely shown an increase of $15 \%$ between 2009 and 2010 (McKinsey, 2009; FT, 2008; IAB, 2010).

Also, the quality of customer service and the resultant virtues of customer satisfaction and loyalty in the online transactions as well as the relationship between the customers in the online media as compared to the offline media. Wind and Rangaswamy (2001), stress that when researchers compare the two advertising environments (online and offline) the online 
Published by European Centre for Research Training and Development UK (www.eajournals.org)

environment appears more attractive in terms of allowing more personalized service and an interactive environment.

Many researchers and academics claim the Internet has led to huge changes in marketing tactics and will continue to do so (Quelch \& Klein, 1996; Hamill, 1997). Specifically, researchers predict that one-to-one marketing and relationship marketing will be extensive (Breitenbach \& van Dore, 1998; Chaigouris, 2000). The popularity of one to one marketing is anticipated as the Internet allows a personal one to one communication between the marketer and the client. Additionally, the concept of mass customization is also strong in the online advertising environment. Since the Internet is quite interactive in nature, it becomes possible and practical for marketers to gain access to information regarding key statistics of customers like their preferences (based on gender, age, locality and income levels) as well as amount of purchases, enabling consumer demographics to be compiled for future use (Cartellerieri et al., 1997).

Company websites are everywhere (Sheehan \& Doherty, 2001). Some of them are present merely to inform, while others aim to sell products thus captivating markets where they do not have a tangible presence. The easy switch between competing brands through online company websites means that firms need to go the extra mile to be able to attract consumers' attention. Hence, the most important factor in online advertising media is the Visual Merchandising of a firm. This is the visual presentation of a company and its inventory to customers visiting the online store (Diamond \& Diamond, 2003). Although there is some research available on the fact that the appearance and characteristic of a web site can have strong effects on the behaviour of shoppers (Eroglu et al., 2003), the exact stimuli for the reactions is as yet not properly examined (McMillan et al., 2003).

Research (Then \& DeLong, 1999) has also investigated the possibility of a similarity in function regarding the visual appearance of a website and the physical layout of a store outlet (Then \& DeLong, 1999). The purpose of these is to induce customers to take a peek inside the store (both physical and virtual), to keep them engrossed and captivated enough to browse and ultimately buy the products. The physical stores have departments housing different products while online stores have categories for their merchandise, all of which essentially perform the same function (Ranganathan \& Ganapathy, 2002). Although the varying a firm offline and online advertising has to be the main area of analysis, it is also necessary to examine the facts beyond them to enable the researcher makes some recommendations. The main aim objective of the present study is to analyse the key factors influencing advertising mediums in the online and offline environments in organisation particularly at Camden Food Co and The Pasty Shop UK

\section{LITERATURE REVIEW}

The use of traditional media to market products may also be referred to as the offline environment. The traditional media are normally understood to be both audio-visual like the television, only audio like the radio as well as print media like the newspapers or the direct mail. Other examples of offline advertising media include company brochures, radio, magazines, branding campaigns and leaflets, to name a few. Research by Epsilon (a European research bureau) reveals that youth between the ages of 18 and 34 would prefer to receive

ISSN 2055-0219(Print), ISSN 2055-0227(online) 
messages regarding a variety of new products and deals through the offline media rather than the online media, with a few exceptions (Leggatt, 2010). The key reasons why offline advertising looks good and attractive are due to the tangibility, networking and interconnectivity, target audience and creativity that it may invent. The term 'online advertising' is used to refer to any such activity that is performed electronically, more typically over the Internet. Using online sources for advertising have led to extremely profitable results and this is why every year, there is an increase in advertising budgets. In 2010, the internet represented $16 \%$ of the total budget for advertising and it is expected that within a time period of four years, this growth will go above $21 \%$ annually (PricewaterhouseCoopers, 2010). One of the key factors that are responsible for this significant growth in advertising budget is the composite tools of search engines and performance tools such as emails and so on.

Advertising was and always has been. It took a nosedive by the end of the Second World War, perhaps even before that when the stock market crashed, followed by the Great Depression in its wake and immediately following that, the Second World War. Once the economy stabilised somewhat in the late 1940s and the Baby Boom was recognised, advertising again began to flourish. The development of the television took advertising to unprecedented heights (Cappo, 2003), setting its priorities in a new light and introducing the audio/video commercial as opposed to solely the audio commercial in the radio and the visual advertisement in the print media. Yet the fact remains that research reveals that traditional forms of advertising are quickly losing appeal as well as effectiveness (Nail, 2005). According to a survey, between September 2002 and June 2004, consumer preferences towards advertising nosedived. Nail (2005) states that in the survey less than $40 \%$ people felt that advertisements should be used to promote new product information while $59 \%$ of the people stated that they were not affected by the commercials they saw in their decision to purchase the product. Regarding the entertainment value of advertising (purely for the sake of recording) less than $49 \%$ people felt that the commercials were entertaining.

All types of companies rely on a medium for marketing their products. The advertising process began with the print media and has now entered the online media. Even though online media is gaining great popularity, traditional media are still used by the online companies as well for promotion. For instance, onsale.com used television to launch an extensive marketing and advertising campaign to promote its website (Korper \& Ellis, 2001). Similarly, there are many other online firms that use television and the print media to enhance sales. Companies normally use business cards, the print media, business mailings, as well as the yellow pages to advertise offline and they use the internet for online advertising.

The offline media that is used for advertising include such vehicles as newspapers, billboards, banners, the radio, the cinema, flyers, direct mailings and so on. There does not seem to any special formula regarding the frequency of advertisements through the use of the offline media. Rather, for such vehicles as billboards and signposts, or wall space, the advertisements tend to remain fixed while the same advertisements in the print media and the television appear cyclical. The traditional media cater to a wide range of people, yet the interaction is quite impersonal and no direct association between the customer and the message is formed.

Marketers face intense pressure to show empirical evidence corresponding to the success of advertising campaigns on product sales and hence financial performance. This is because of 
Published by European Centre for Research Training and Development UK (www.eajournals.org)

the insubstantial proof regarding positive financial performance as a consequence of spending on advertising (Hanssens, Parsons\& Schultz, 2001). Studies indicate that intense advertising of new products can instantly help customers identify with it (Srivastava, Shervani \& Fahey, 1998). In this regard, Bly (1993) states that the "new-product innovator will spend more than twice as much on advertising and promotion as a business with fewer new products (p125). Alternatively, advertising helps in smoothing out demands for seasonal products, through reinforcement and accentuation (Fischer, Shin \& Hanssens, 2007). Advertising also supports differentiation of products enabling companies to charge competitive prices (Boulding, Lee \& Stalin, 1994). Research also indicates that advertising works best when customers are given a new product (Lodish et al., 1995), especially if the product is new to the market as opposed to new to the firm, it can reap innumerable future profits and gain a competitive edge permanently in the market (Hanssens \& Ouyang, 2002).

\section{Advertising through the Offline media:}

First and foremost, how does a marketer track the effect of offline advertising? Offline advertising may use the mediums of individual telephone/ mobile numbers or keep a track of coupons at the most, to measure the effects on customer responses. Yet, for television commercials, there does not seem to any quantifiable method to assess how many viewers have been affected to translate into financial opportunities (Vignes, 2008). The reason why it becomes difficult to quantify the effects of traditional advertising is explained by Ryan and Rae (2005) as being a complex one. First of all, advertising itself serves many purposes like creating awareness for a product or service, enhancing brand equity and encouraging sales. None of these aims is easily quantifiable in terms of measurement in response to the advertising that it may have resulted from. The authors state a number of other important reasons like the explosion of the choices within the same medium (like television expanding from a few to hundreds of different channels or newspaper firms doubling and new magazines springing up for special interest groups and so on) as well as various choices of mediums like the offline and the online media. Advertisers now have a multitude of media through which to convey their messages and often use an optimum combination for targeting their audience.

\section{Advertising and the Internet:}

One of the first proponents of the Internet were the early advertisers who saw the scope for reaching individual targets but on a much wider scale than envisaged by the traditional media. The initial capitalisation of the online advertising market soon gave way to negativity but resurgence was witnessed again by 2004 (Forrester, 2001; The Wall Street Journal, 2003). The purpose of this study is to evaluate the reasons why advertisers use both the online and offline media for advertising of their products, what is the frequency of the advertising mechanism and how advertisers vary it to use the advertising effectively.

There has been a marked increase in online advertising with the general increase in web services, and consequently behavioural targeting is being focused onto better understand the demographics of the online customers (Yan et al, 2009). The study took the definition of 
Published by European Centre for Research Training and Development UK (www.eajournals.org)

Behavioural Targeting from Wikipedia, which it stresses is a good source of BT related literature, as 'BT uses information collected on an individual's web-browsing behaviour, such as the pages they have visited or the searches they have made, to select which advertisements to display to that individual. Practitioners believe this helps them deliver their online advertisements to the users who are most likely to be influenced by them' (Yan et al. 2009, p262). Behavioural targeting is important to advertisers as it enables the marketers of a product target appropriate users based on their online behaviours. TM advertising for example (Baker, 2004) reveals that compared to normal web-based advertisements, behavioural targeting shows $115 \%$ increase in business traffic, as well as $3 \%$ more aware online users as compared to normal web-based advertisement viewers. The demographic information used depends on certain factors (like ease of availability), the most basic of which are gender, age, geographical location and area of interest.

\section{Types of entrance for online advertising a firm can use}

News sites: News sites are considered ideal as they provide online information on both local aspects as well as giving international news. Additionally, such sites also display classifieds, news related to arts and entertainment, shopping information, sports updates and so on. Visitors to these sites are normally considered more mature with a higher level of education.

Online magazines: Like their counterpart online news portals, online magazines also present a high degree of opportunity to maximize the number of advertisements that can attract clients to respond. The content matter is important and the advertisements displayed relate quite closely to the content matter discussed. Advertising revenue is generated when any of the advertisements gets viewed or 'clicked'. The magazine may be general in nature or it may specialise in a particular content matter, like sports, computers and so on.

Search engines: Search engines are typically used by a vast number of people to locate websites and general information, rather than using directories. As such, search engines cater to all ages and manner of people who may be of any gender, class or educational level. Some of the more popular search engines include Google, Yahoo, etc.

Online advertisements are also quite beneficial in boosting offline sales, rather than the traditional or Offline media (Abraham, 2008) by helping to increase sales at the physical brick and mortar stores of many firms as opposed to their online websites. This is an important insight as it enables companies to make use of both the traditional media as well as online media to stimulate sales both within the same medium (online advertising on online sales) as well as across the two mediums (online advertising on offline sales). In this regard, although there are many efforts to drive up company sales through the same medium (online advertising to boost online sales and print advertising and commercials to boost offline sales), the combined efforts may have an impact on sales for a firm through both mediums.

However, advertising can effect through the same medium (online). This means the effect of traditional or offline advertising on offline sales and the effects of online advertising on online sales. In this regard, Assmus, Farley \& Lehmann (1984) analysed 128 cases based on traditional media to reveal short-period elasticity at an average of 0.22 while the carry-over effect was 
evaluated at 0.46. Subsequent to this research and following on from 1984 for a period of 25 years; Sethuraman, Tellis and Briesch (2011) studied 751 cases of the effects of traditional media (specifically print, Television and other offline media) to reveal a short-term elasticity calculated at 0.12 , while the mean long-term elasticity was calculated at 0.24 . Both these elasticity are lower for the same duration in the Assmus, Farley \& Lehmann (1984) studies.

Online advertisements are also quite beneficial in boosting offline sales, rather than the traditional or Offline media (Abraham, 2008) by helping to increase sales at the physical brick and mortar stores of many firms as opposed to their online websites. This is an important insight as it enables companies to make use of both the traditional media as well as online media to stimulate sales both within the same medium (online advertising on online sales) as well as across the two mediums (online advertising on offline sales). In this regard, although there are many efforts to drive up company sales through the same medium (online advertising to boost online sales and print advertising and commercials to boost offline sales), the combined efforts may have an impact on sales for a firm through both mediums. However, advertising can effect through the same medium (online). This means the effect of traditional or offline advertising on offline sales and the effects of online advertising on online sales. In this regard, Assmus, Farley \& Lehmann (1984) analysed 128 cases based on traditional media to reveal short-period elasticity at an average of 0.22 while the carry-over effect was evaluated at 0.46 . Subsequent to this research and following on from 1984 for a period of 25 years; Sethuraman, Tellis and Briesch (2011) studied 751 cases of the effects of traditional media (specifically print, Television and other offline media) to reveal a short-term elasticity calculated at 0.12 , while the mean long-term elasticity was calculated at 0.24. Both these elasticity are lower for the same duration in the Assmus, Farley \& Lehmann (1984) studies.

The authors explained the decrease in the elasticity due to higher maturity of the offline market with the passage of time, even if the concerned firms had been achieving optimal advertising success in the past. The higher maturity level has been reached in part as a consequence of "'increased competition, ad clutter, the advent of the Internet as an alternate information source' (Sethuraman, Tellis and Briesch, 2011; 460). Normally, the customer is bombarded with ad clutter, which is taken to mean the display of a large volume of advertisements for the customer. Obviously, this is not a very desirable state of affairs for either the advertiser or the consumer, as the advertisers' efforts and finance are wasted when the consumers find such bombardment undesirable (Ha, 1996). Hence, advertising clutter is taken to mean a 'high degree of intrusiveness' (Ha \& McCann, 2008) and has been defined through the three dimensions of 'quantity, intrusiveness and competitiveness' (Ha, 1996).

Sethuraman et al (2011) also find that the advertising elasticity (that they calculated using their own formulated statistical model):

remains unaffected during recession

is higher for non-perishable goods as compared perishables

is higher for new products as compared to mature stage products 
The author during his research for this literature reviewed that the studies conducted to find the effects of online advertising have basically concentrated on the level of awareness of the brand that such advertisements have generated (Cho, Lee \& Tharp, 2001; Dreze \& Hussherr, 2003). One study however does measure and tabulate the results of online advertising on online purchase of products. Manchanda et al (2006) constructed a unique statistical model to examine the effects of advertising on the level of weekly purchase of a set of existing customers. The study found that unlike what was previously thought, the online advertising does have an important consequence on the probability of online purchase. The study was conducted through a highly sophisticated and statistical model created by the authors of the study as they consider the prevailing measures like click-through to be weak assessors of consumer behaviour. There is also evidence presented of the occurrence of heterogeneity among a given set of consumer as a result of exposure to online advertising. This means that the research shows that consumers respond highly to ad weights seconded by number of special exposure sites, and this is where marketers should be focusing on to generate higher online sales through online marketing.

Other than advertising, there is increasingly another form of marketing which is quickly catching up- the electronic (Word Of Mouth) through the social networking medias like twitter, Facebook and some other networking communities being instrumental in shaping consumer decisions (Witzig \& Spencer; Carroll and Ahuvia, 2006; Datta et. al., 2005; Goldenberg et al, 2001; Yamamoto \& Matsumura, 2011). Social networking sites or social media as they are popularly called are started by a member or group of members that invite other like-minded individuals to join their group and share similar tastes and opinions (Trusov et al. 2009). Social media have been recognised as important sources for advertising for the following key reasons (Yamamoto \& Matsumura, 2011):

\footnotetext{
$\square \quad$ they give product and services information

$\square \quad$ they build customer relationships through WOM/ referrals

$\square \quad$ they can enables firms to build interactive relationships with both existing as well as potential customers
}

they are a cost-effective alternative to traditional media

Hence, the latest advertising campaigns are now conducted through the Internet leading to a move in investment from the offline media to the online media (Datta et al, 2005; Mason, 2008; Trusov et al, 2009). Research on this area of advertising is quite limited, to the point of being non-existent (Trusov et al., 2009) although there have been a couple of studies directed towards this area. Jansen et al (2009) used Twitter to identify the feelings of a writer with respect to a brand. Asur \& Huberman (2010) used Twitter fan information and exchange to make successful predictions regarding movie revenues at the box office, even before the films were released. Likewise, Tumasjan (2010) followed Tweets to get a better understanding of the numerical assessment of political affiliations, finding that election results could be forecast accurately through the number of messages exchanged on the political affiliations.

The reason why the social media are increasingly being used effectively is quite logical. For the promotion of this aim, the companies use various categories of marketing to promote their product through both offline and online channels. Hence they use a combination of the various 
Published by European Centre for Research Training and Development UK (www.eajournals.org)

media to encourage the achievement of the corporate goal (Yamamoto \& Matsumura, 2011). Some research has been conducted to show the effect of digital advertising on offline sales (Pauwels et al, 2011; Van Nierop et al, 2011) and vice versa, that is offline advertising on online sales (Trusov et al. 2009; Naik Peters, 2009). Additionally, research by Ansari et al. (2008) tabulates cross channel effects of advertising through both the online and the offline mediums.

The question of how effective is one media compared to the other is an important one. Although online media are currently considered as more powerful than traditional media (Port 1999, Hoffman \& Novak, 1996), there is evidence to suggest that consumers react to advertisements in the same manner irrespective of whether the advertisement is viewed through the offline or the online media. With reference to this statement, Dreze \& Hussherr (2003) found that audience typically responded in the same manner to online advertising as to advertising in the other media, further concluding that online advertising is capable of being ignored more easily than the advertisements in other media. Alternatively, Lynch \& Ariely (2000) found that people are not bothered by price if online advertisements offer different products than traditional media.

\title{
METHOD
}

For the purpose of this paper, secondary data such as the annual reports and other operational reports of the two organisations in the last 5 years was used in the analysis.

\begin{abstract}
ANALYSIS
The key aim of this research was to analyse factors that exist in the advertising mediums, both in the online and the offline environments, specifically with regard to two different business models Camden Food Company and The Pasty Shop, as well as to evaluate the concept of customer satisfaction and generation of loyalty through the two environments, either through a combination of the two, or as sole mediums. It was discovered that both the firms considered can be considered unique business models and brands in their own genre. The size of the brand varies though, with The Pasty Shop being the larger of the two. Notwithstanding, both have made their presence felt in terms of healthy and good quality food for people on the go, specifically at railway stations. Both brands have online presence through an official website. Other than that, there is nothing specific in terms of online advertising and the offline medium of advertising has only been used quite recently. In fact until the last year, there was nothing in terms of advertising to promote either of the brands, both relying on the quality of their product and commuters and travellers from the stations for sales.
\end{abstract}

\section{The key marketing methods used:}

Online Medium: Both the companies maintain websites that are easy to navigate and give detailed information regarding the variety of products, the locations where the stores can be found as well as a brief introduction about the philosophy of both the brands. The management feel that at the present stage, the online medium is expensive to maintain and run, requiring 
substantial budgets. If the management spends such expensive budgets with customer awareness still remaining low, it would have lost funds that could be allocated more efficiently on the offline medium. A visit to the official websites of both the brands reveals many similarities- both are descriptive in nature, and do not use Visual Merchandise Display to promote their products. In the case of The Pasty Shop, although a 'Visual Display' of the pasty is given, there is also the statement, 'to the naked eye one pasty might look like another but inside they are completely different' (www.thepastyshop.com).

Offline Medium: Both the companies advertise through the use of visual advertisements at stations, at the Metro as well as the use of radio. Variation in the frequency of advertising is achieved through following a strategy based on such factors as the seasons, their effect on the commuters (students, professionals, and an estimate of the number of people that may commute at a given time through a given point) and so on.

As far as the evaluation of the superiority of one advertising medium over the other is concerned, the two cases studied do not have much in terms of correlation evaluation as the online medium has only been used for providing information about the brand. The offline medium has also not been used extensively, only recently being used for advertising purposes. When the writer considers how one form of advertising competes with the other in gaining a competitive edge, the writer does not find enough evidence to be able to gauge this objective on a rational note. Both the brands have never used any form of online advertising; thereby leading to the conclusion that the offline advertising that is being used may have been able to give a competitive edge, so that the brands do not wish to consider using an online environment to augment sales. Additionally, on an assessment of whether both the unique business models prefer to use the combined environments (both offline and online) simultaneously, the author finds that the usage gives the brand a leverage. Suppose a customer A has been to one of the brands and has had a positive experience. Studies reveal that offline advertising has a positive impact on, and even increases the effectiveness of online advertisements, casting them as a sort of "substitute" for the format presented offline

In the case of both Camden Food Co and The Pasty Shop both the online and the offline mediums are being used although the degree of advertising is not as high as many other brands. The online medium of advertising is solely used for imparting information regarding the brand while offline advertising has been used based on research of the points where the highest number of customers will be commuting at any specific time. It is also interesting to note that both the companies are not averse to employing independent media houses if the management feels that there exists a potential for advertising through multiple channels. To date, although no effort has been made to seriously advertise online, the Director for Marketing and Advertising, Mr Richard Kirk has not ruled out the possibility of using creative variants of the offline advertising medium for online advertising as well.

The Director has further made an observation 'there hasn't been much scope with keeping websites operational and up-to-date'; when a web-site is created, there is more to it than only imparting information. Although the initial process requires time, well-thought out plans as well as implementation, there are other considerations too. It should be easy to navigate as well as being able to address the needs of the customers. Once the web-site becomes operational, the real challenge is to update and maintain the site- the principal consideration for online 
Published by European Centre for Research Training and Development UK (www.eajournals.org)

maintenance is the company's marketing policy and the objectives that are hoped to be achieved through sales. Regular maintenance of the site encourages visitors, while poor maintenance may result in a loss of visitors.

\section{CONCLUSION}

In both the cases of Camden Food Co and The Pasty Shop, the author feels that due to the nature of the brand, the management finds more scope in the offline medium of advertising as they feel that there is more exposure with visibility rather than through online advertising. This is possibly because both the eateries are for people who are commuters and in-transit, rather than places where people would formally go out to dine. Hence, since the genre of both the brands is unique, competition is based more on the quality of the product rather than on pricing alone. Both the brands endorse healthy eating habits and encourage commuters to think of their diets irrespective of the excuse of 'being on the go'. Compared to most of the 'fast-food' brands competing in the same genre, both Camden Food Co and The Pasty shop provide healthier options.

\section{REFERENCES}

Ansari A., Carl F., M. \& Scott A., N. (2008), Customer Channel Migration, Journal of Marketing Research 45 (1) p 60-76.

Baker L., (2004), Behavioral Targeting and Contextual Advertising, Search Engine Journal [Online]. Available at: http://www.searchenginejournal.com/behavioral-targeting-andcontextual-advertising/836/ (Accessed: 19 Dec 2011)

Bergemann D. \& Bonatti A. (2011), Targeting advertising markets: implications for offline versus online media, RAND Journal of Economics 42 (3) p 417-443.

Camden Food (n.d.) http://www.camdenfoodco.com/ (Accessed: 11 March 2012)

Carroll. B. \& Ahuvia, A. (2006), Some antecedents and outcomes of brand love, Market Letters 17 (2) p79-89

Cartellerieri, C., Parsons, A., Rao, V., Zeisser, M. (1997), The real impact of Internet advertising, The McKinsey Quarterly (3) p44-63

Chaigouris, L. \& Wansley, B. (2000), Branding on the Internet, Marketing Management 9(2) p34-9

Cho, C., J. Lee \& M. Tharp (2001), Different Forced-Exposure Levels to Banner Advertisements, Journal of Advertising Research 41(4) p45-56

Cooper D.R. and Schindler P.S. (1998), Business Research Methods. 6th edn. Irwin: McGraw Hill

Cooper D. R. and Schindler P. S. (2011), Business Research Methods. 11th edn. Irwin: McGraw-Hill

Craig S. B. \& Doris C. Van Doreen (1998), Value-added marketing in the digital domain: enhancing the utility of the Internet, Journal of Consumer Marketing 15 (6) p558 - 575

Creswell, J.W. (2003), Research design. Qualitative, quantitative and mixed methods approach. Thousand Oaks, CA: Sage.

Crotty, M. (1998), The Foundations of Social Research. Australia: Saga Publications Ltd 
Published by European Centre for Research Training and Development UK (www.eajournals.org)

Datta, P. R., Chowdhury, D. N., \& Chakraborty, B. R. (2005), Viral marketing: New form of word of-mouth through Internet, The Business Review Cambridge 3(2) p69-75.

Diamond, J. and Diamond, E. (2003), Contemporary Visual Merchandising Environmental Design, 3rd edn. Upper Saddle River: Prentice Hall

Dreze, Xavier \& F. Hussherr (2003), Internet Advertising: Is Anybody Watching? Journal of Interactive Marketing 17 (4) p8-23

Eroglu S., A., Machleit K., A. \& Davis L., M. (2003), Empirical Testing of a Model of Online Store Atmospherics and shopper responses, Psychology \&Marketing 20 (2) p139-50.

Goldenberg, J., Libai, B., \& Muller, E. (2001), Talk of the Network: A Complex Systems Look at the Underlying Process of Word-of-Mouth, Marketing Letters 12(3) p211-223.

Greenspan, R. (2002), 'E-shopping around the world, July. [Online]. Available at: www.cyberatlas.com (Accessed: 10 March 2012)

Hanssens, Leonard J. Parsons, and Randall L. Schultz (2001), Market Response Models: Econometric and Time Series Analysis, 2nd edn, Boston: Kluwer Academic Publishers

Hoffman, Donna L. \& Thomas P. Novak (1996), Marketing in Hypermedia ComputerMediated Environments: Conceptual Foundations, Journal of Marketing, 60 (3) p5068.

Ilfeld, J.S. \& R.S. Winer (2002), Generating Website Traffic, Journal of Advertising Research 42 (5) p49-61.

Jim H. \& Karl G. (1997), Internet Marketing in the Internationalisation of UK SMEs, Journal of Marketing Management, 13(1-3) p9-28

Leggatt, H. (2010). Don't ignore offline media when targeting young adults. Available: http://www.bizreport.com/2010/09/dont-ignore-traditional-media-when-targetingyoung-adults.html (Accessed: 9 March 2012)

Lynch, Jr. J. G. \& Dan A. (2000), Wine Online: Search Costs and Competition on Price, Quality, and Distribution, Marketing Science, 19 (1) p83

Macy's (2011), "Macy's, Inc. Same-Store Sales Up 6.7\% in June,” (July 7, 2011). [Online]. Available at: http://phx.corporateir (Accessed: 6 March 2012)

Manchanda et al., (2006), The effect of banner advertising on Internet purchasing, Journal of Marketing Research, 43 (1) p98-108

Mason, R., B. (2008), Word of mouth as a promotional tool for turbulent markets, Journal of Marketing Communications, 14 (3) p207-224.

McMillan S., J., Jang-Sun H. \& Guiohk L (2003), Effects of Structural and Perceptual Factors on Attitudes toward the web site, Journal of Advertising Research 43 (4) p400-409.

McMillan, S., Hwang, J. and Lee, G. (2003), Effects of structural and perceptual factors on attitudes toward the website, Journal of Advertising Research 43 (4) p400-409.

Michel de, R. (2009), 'Managing regulation in a new era', McKinsey Quarterly (2), p10-10.

Miles, M. Hurberman, and M. (1994), Qualitative Data Analysis: an expanded sourcebook, London: Beverley Hills

Net/phoenix.zhtml? c=84477\&p=irol-newsArticle\&ID=1582922 (Accessed: 9 March 2012)

Oppenhiem A., (1992), Questionnaire Design, interviewing and attitude management, USA: Continuum

P. Kalakota, \& A., B., Whiston (1996), Electronic Commerce: a Manager's Guide, AddisonWesley, Reading: MA

Pauwels, Koen, Peter S.H. Leeflang, Marije L. Teerling, and K.R. Eelko Huizingh (2011), "Does Online Information Drive Offline Revenues? Only for Specific Products and Consumer Segments!” Journal of Retailing, 87 (1), pp1-17 
Published by European Centre for Research Training and Development UK (www.eajournals.org)

Polit, D.F., Beck, C.T. and Hungler, B.P. (2001), Essentials of Nursing Research: Methods, Appraisal and Utilization. 5th edn. Philadelphia: Lippincott Williams \& Wilkins

Port, Otis (1999), "Customers Move Into the Driver's Seat," Business Week, (October 4), pp. 103-106

Pricewaterhouse Coopers (2010), PricewaterhouseCoopers Global entertainment and media outlook: 2010 - 2014 | 2010

Punch, K. (2000), Developing Effective Research Proposals. London: Sage

Quelch, J. and Klein, L. (1996), "The internet and international marketing”, Sloan Management Review, 37 (3) p60-75.

Ranganathan, C. and Ganapathy, S. (2002), "Key dimensions of business-to-consumer web sites",Review, Vol. 37, pp. 60-76.

Ryan \& Rae, (2005), Quantifying advertising's impact. [Online] Available at: http://www.imediaconnection.com/content/7543.asp (accessed: 19th February, 2012)

Sethuraman et al., (2011), 'How well does advertising work? Generalizations from metaanalysis of brand advertising elasticities", Journal of marketing research, volume 48, No 3

Sheehan \& Doherty (2001), Re-weaving the Web: Integrating print and online communications. Journal of Interactive Marketing, 15 (2), p 45-79.

Sherman, L. and J. Deighton (2001), "Banner Advertising: Measuring Effectiveness and Optimizing Placement," Journal of Interactive Marketing, 15 (2), pp60-64.

Silk, A.J., L.R. Klein, and E.R. Bernt (2001), "The Emerging Position of the Internet as an Advertising medium," Netnomics, 3 (2), pp129-48.

The Pasty Shop (n.d.) http://www.thepastyshop.com/ (Accessed: 11 March 2012)

Then, N.K. and DeLong, M.R. (1999), “Apparel shopping on the web”, Journal of Family and Consumer Science, Vol. 91 No. 3, pp. 65-8.

Trochim, W., (2006), Introduction to Design. [Online]. Available at: http://www.socialresearchmethods.net/kb/desintro.htm [Accessed: 10 Jan 2011]

Trusov, M., Bucklin, R., \& Pauwels, K. (2009). Effects of word-of-mouth versus traditional marketing: Finding from an Internet social networking site. Journal of Marketing, 73 95), p90-102.

U.M. Dholakia, L.L. Rego, (1998) What makes commercial web pages popular? An empirical investigation of web page effectiveness, European Journal of Marketing 32 (7/8), pp.724-736.

Van Nierop, J.E.M., P.S.H. Leeflanga, M.L. Teerling and K.R.E. Huizingh (2011), “The impact of the Introduction and Use of an Informational Website on Offline Customer Buying Behaviour," International Journal of Research in Marketing, 28 (2), 155-165.

Veal A.J, (2006), Research Methods for Leisure and Tourism - A practical guide, 3rd edn, UK: Pearson Education Limited

Vignes, B., (2008), Internet advertising vs. traditional advertising. [Online]. Available at: http://www.ghotibait.com/internet-marketing/internet-adversiting-vs-traditionaladvertising/ (accessed 19 Feb 2012)

Yan et al., (2009), How much can behavioural targeting help online advertising? In proceeding of WWW'09 (Madrid) ACM Press, 261

Yang, C.C., (1997), An exploratory study of the effectiveness of interactive advertisements on the Internet, Journal of Marketing Communications 3(2) p 61-85. 